\title{
Antibiotic prescribing among patients with severe infectious diseases in two private sector hospitals in Central India - A time series analysis over 10 years
}

\author{
Anna Damlin \\ Karolinska Institutet https://orcid.org/0000-0002-8124-5864 \\ Megha Sharma ( $\triangle$ meghasharma27@rediffmail.com ) \\ https://orcid.org/0000-0001-9165-9393
}

\section{Gaetano Marrone}

Karolinska Institutet

Cecilia Stålsby Lundborg

Karolinska Institutet

\section{Research article}

Keywords: Anti-Bacterial Agents, Bacterial Infections, Drug Resistance, Drug Combinations.

Posted Date: February 13th, 2020

DOI: https://doi.org/10.21203/rs.2.17305/v2

License: (c) (i) This work is licensed under a Creative Commons Attribution 4.0 International License. Read Full License

Version of Record: A version of this preprint was published at BMC Infectious Diseases on May 13 th, 2020. See the published version at https://doi.org/10.1186/s12879-020-05059-7. 


\section{Abstract}

Background: Antibiotic resistance is an emerging problem caused due to antibiotic use. In countries with high rates of infectious diseases, antibiotic resistance is a frequent cause of mortality. The aim was to analyse antibiotic prescribing practices between 2008 and 2017 in a teaching (TH) and a non-teaching (NTH) hospital, as typical hospitals of low- and middle-income countries, and to compare antibiotic prescribing for severe infectious indications for which empiric antibiotic treatment is recommended.

Methods: Data from adult patients registered at two Indian private-sector hospitals with one of the following indications: epiglottitis, pneumonia, peritonitis, pyelonephritis, cellulitis, erysipelas, septic arthritis, endocarditis, meningitis or sepsis; were included and analysed. Antibiotic prescription data was analyzed using the World Health Organization's (WHO) Anatomical Therapeutic Chemical classification system and the Defined Daily Doses. Chi-square and t-tests were used to compare the data between groups. Time series analyses were conducted using linear regression. P-values $<0.05$ were considered significant.

Results: In total, 3,766 patients were included, 2,504 inpatients in the NTH and 1,262 in the TH, of which $92 \%$ and $89 \%$ patients, respectively, were prescribed antibiotics. Sixty-one percent of total prescriptions in the TH and $40 \%$ in the NTH comprised the access category of antibiotics (i.e. the first-choice of treatment according to the WHO). The WHO's second-choice of treatment, the watch category, comprised $29 \%$ and $40 \%$ of total prescriptions in the TH and NTH, respectively. Prescribing of fixed-dose combinations (FDCs) of antibiotics was significantly higher in the NTH $(18 \%)$ than in the TH $(8 \%, P<0.05)$. Prescribing of watch antibiotics and FDCs increased significantly in both hospitals between 2008 and 2017 among patients with pneumonia, cellulitis and peritonitis $(P<0.05)$.

Conclusions: Prescribing of watch antibiotics and FDCs of antibiotics increased over time at both hospitals, indicating under prescribing of access antibiotics and more prescribing of second-choice antibiotics. The results can be used to highlight the areas of improvement in similar settings. Implementing diagnostic routines and local prescribing guidelines could improve the prescribing practices.

\section{Background}

Antibiotic resistance is an emerging global threat, as it causes significant morbidity and mortality worldwide $[1,2]$. In an antibiotic surveillance report between 2016 and 2017 that focused on 22 countries, bacteria resistant to at least one of the most commonly used antibiotics were identified in patients diagnosed with bloodstream infections [3]. According to the World Health Organization (WHO), there is a need for global action against antibiotic resistance to ensure the effectiveness of antibiotic treatment in the future [4].

In low- and middle-income countries (LMICs), the infectious disease burden is often high, and antibiotic resistance is one of the common causes of mortality among patients with infectious diseases [2,5]. Tackling antibiotic resistance requires costly equipment for microbiological analyses to determine the susceptibility of bacteria, and these methods must be implemented and reported [5, 6]. In LMICs, access to diagnostic methods is often limited. Consequently, antibiotics, frequently broad-spectrum antibiotics or fixed-dose 
combinations (FDCs), are commonly prescribed empirically based on a clinical suspicion of infection [7-10]. However, antibiotic resistance is not confined to LMICs.

Improper use of antibiotics contributes to the development of antibiotic resistance. As reported previously, antibiotics should be prescribed only for relevant indications [11]. Furthermore, they should be as targeted as possible and administered at correct doses for appropriate treatment durations and by a suitable route of administration [11]. Mapping of antibiotic prescribing practices can identify areas for improvement. Longterm studies on antibiotic prescribing in LMICs, especially studies comparing practices among various health care providers and in various settings, are scarce [6].

The primary aim of the present study was to present and compare antibiotic prescribing practices over a 10years period in two private-sector hospitals in Ujjain, Madhya Pradesh, India with different settings. The study population was inpatients admitted to the study hospitals with severe infections for which empirical antibiotic treatment is recommended [12]. The hospitals were selected as those were representative of the majority of healthcare facilities in LMICs. A secondary aim was to compare antibiotic prescribing practices for selected indications with global recommendations for antibiotic treatment.

\section{Methods}

\section{Study settings}

This prospective study with time-series analyses was conducted at two tertiary care, private sector hospitals run by the same trust, located in Ujjain district of Madhya Pradesh, India, one teaching hospital (TH) and one non-teaching (NTH). The TH is in a rural area and has 800 beds and the NTH is centrally located with 400 beds. At the TH, patients are provided medical services and medicines free of charge while medical services at the NTH are charged but at a reduced level [13]. At the NTH, the patients purchase their medicines also during hospital stay. Medical representatives are not allowed to visit the prescribers at the TH while they can do so at the NTH. A local essential medicines list was available at the TH, though it was not completely implemented but no local prescribing guidelines were available at the TH or NTH. As none of the hospitals had computerized prescribing records, data was manually registered in a form inserted in each patient's medical file at time of admission, and prospectively filled during the patients stay in the hospital. This was made by trained nursing staff that completed forms continuously, which has been described in detail earlier $[9,13]$.

\section{Categorization of antibiotics}

Prescribed antibiotics were classified using the Anatomical Therapeutic Chemical classification system (ATC) and the Defined Daily Doses (DDD) classification (2019) according to the WHO [14]. The WHO has classified antibiotics based on the risk of antibiotic resistance development into so-called access, watch and reserve antibiotic categories $[4,15,16,17]$. This classification of antibiotics was adopted for analysis (Table 1). The aim for the categorization of antibiotics is to sort antibiotics according to how they should be used, based on the risk of development of antibiotic resistance to preserve the effectiveness of antibiotic treatment and to improve clinical outcomes $[4,15,16]$. Access antibiotics should be widely available, affordable and of good 
quality, watch antibiotics include most of the highest priority, critically important medicines and should be used only for specific and limited indications and reserve antibiotics should only be used when all alternative antibiotics have been unsuccessful for the treatment $[4,15,16]$. Some of the prescribed antibiotics are categorized only up to antibiotic-groups level, these antibiotics were added to the relevant category as per their antibiotic-groups. For example; cefuroxime was not categorized by the WHO but second generation cephalosporins were categorized as access antibiotic, then we added cefuroxime to the access category for the analysis [17]. Since FDCs consist of at least two antibiotics, often from different antibiotic-groups, we added "FDCs" as a category beside the access, watch and reserve antibiotics. Antibiotics categorized in the respective categories are presented in Table 1.

\section{Table 1 should be inserted here, it is now placed in the end of the manuscript, since it is larger than one page according to the submission guidelines.}

\section{Data analysis}

Antibiotic prescribing data was collected prospectively from the records of all patients, admitted to the TH and the NTH between April $1^{\text {st }} 2008$ and May $22^{\text {nd }} 2017$. The study population comprised inpatients with severe infections for which empiric antibiotic treatment was indicated by the WHO [15]. Data from all adult patients ( $\geq 18$ years) that stayed at least one night in either hospital, and diagnosed with any of the following infectious indications- epiglottitis, pneumonia, peritonitis, pyelonephritis, cellulitis, erysipelas, septic arthritis, infective endocarditis, meningitis and sepsis were screened for the analyses. However, fewer patients were registered with epiglottitis, pyelonephritis, erysipelas, septic arthritis, infective endocarditis and meningitis, therefore, data from the inpatients with pneumonia, peritonitis, cellulitis and sepsis were selected for detailed analysis. A unique code was generated for each patient record, without identifying the patients individually, thus all data were anonymized. Patient data were analyzed for gender, duration of hospital stay and if antibiotics were prescribed or not during hospital stay. The antibiotic prescription data were analyzed for type of antibiotic, dose, treatment duration, frequency and route of administration. To analyze the adherence to prescribing guidelines, existing international guidelines for empiric antibiotic prescribing were used. The WHO has developed international guidelines for empirical treatment of cellulitis and pneumonia [15]. For peritonitis, the World Society of Emergency Surgery has published guidelines for empirical antibiotic treatment and likewise, the Surviving Sepsis Campaign has published international guidelines for sepsis $[18,19]$.

Prescribed antibiotics were grouped for their first 4-5 characters of their ATC-code: J01A, J01B, J01C group 1 (containing all antibiotics starting with J01CA to J01CG), J01CR, J01D, J01E, J01F, J01G, J01M, J01R and J01X (Table 1) [14]. The J01R contained the FDCs of antibiotics that has been listed in the ATC/DDD classification system until June 2019. Prescribed antibiotics were also classified for: access, watch, reserve and FDCs of antibiotics (Table 1) $[4,15,16]$. Antibiotic prescribing was calculated for in DDDs and DDD per 1000 patient days according to following formulas:

\section{See formulas in the supplementary files.}

Time series analyses were conducted using linear regression for antibiotic prescribing in DDD per 1000 patient days during 2008-2017. Time series analysis were made for different patient groups; all included 
patients at the NTH and the TH respectively and patients with cellulitis, peritonitis, pneumonia and sepsis at the NTH and the TH respectively, as these were the most common infectious diagnoses among patients at both hospitals. Analyses were done both for total antibiotic prescribing among these groups and for prescribing of access, watch, reserve and FDCs of antibiotics. Linear regression was used with DDDs per 1000 patient days as outcome (dependent variable) and year as independent variable to obtain a slope for the trend during 2008-2017. For categorical variables, frequencies and percentage were calculated. For numerical variables, sum and mean with its $95 \%$ confidence interval $(\mathrm{Cl})$ were calculated. Chi-square test (for categorical variables) and t-test (for continuous numerical variables) were used to compare the data between the two hospitals and between the patient groups. Pearson chi-square was used for expected values $>5$ and Fischer's exact test for expected values $<5$. P-values $<0.05$ were considered statistically significant. Data was entered manually in EPI Info 3.1 and analyzed using STATA software version 15.1 (Stata Corp. College Station. Texas. USA).

\section{Results}

In total, 134,666 patients were admitted to the NTH, and 109,108 patients were admitted to the TH between 2008 and 2017. Data from 3,766 patients were included in the analysis (NTH: $n=2,504 ; \mathrm{TH}: n=1,262$, Table 2). Antibiotics were commonly prescribed in both hospitals, although a significantly higher percentage of patients admitted to the NTH were prescribed antibiotics as compared with those admitted to the TH ( $89 \%$ at the $\mathrm{TH}, 92 \%$ at the NTH, $\mathrm{P}<0.05$ ) (Table 3). Among the different diagnostic groups, there were no differences in antibiotic prescribing practices between the hospitals, except for meningitis, where $90 \%$ of the patients in the NTH were prescribed antibiotics as compared with $70 \%$ in the TH $(P<0.05)$. The number of antibiotic prescriptions per patient in the TH was higher than that in the NTH. The average number of antibiotic prescriptions, i.e. prescription of one specified antibiotic with stated dose, frequency and duration in days, per patient was 22 in the TH and 8 in the NTH (Table 3). The duration of the hospital stay of the patients in the TH was higher than that of the patients in the NTH (mean 10.1 days at the TH and 4.4 days at the NTH, P $<0.05)$.

Prescribing of antibiotics for all indications increased between 2008 and 2017 in the NTH $(P<0.01)$, whereas prescribing practices did not change significantly during this period in the TH $(P=0.07$, Figure 1 , Table 4$)$. Antibiotics included in the access category comprised $61 \%$ of the total antibiotics prescribed in the $\mathrm{TH}$ and $40 \%$ of the total prescribed in the NTH ( $P<0.01$, Figure 2, Table 4). Prescribing of access antibiotics increased in the NTH between 2008 and 2017. Prescribing of antibiotics categorized as watch antibiotics comprised $29 \%$ of the total antibiotics prescribed in the TH and $40 \%$ of the total prescribed in the NTH. Prescribing of watch antibiotics rose in both hospitals between 2008 and 2017 ( $P<0.01$ for both hospitals, Figure 2, Table 4). Reserve antibiotics comprised less than one percent antibiotics prescribed in both hospitals. However, prescribing of reserve antibiotics increased between 2008 and 2017 in the TH $(P<0.01$, Figure 2, Table 4).

The overall antibiotic prescribing among all included patients increased from 2008 to 2017 at the NTH ( $P$ $<0.01)$ but did not significantly change at the TH $(P=0.07$, Figure 1 , Table 4). Antibiotics included in the access category comprised $61 \%$ of the total antibiotic prescribing at the TH and $40 \%$ at the NTH. Prescribing of access antibiotics increased at the NTH from 2008 to 2017 ( $P<0.01$, Figure 2, Table 4). Prescribing of 
antibiotics categorized as watch antibiotics comprised $29 \%$ of the total antibiotic prescribing at the TH and $40 \%$ at the NTH. Prescribing of watch antibiotics increased at both hospitals from 2008 to 2017 ( $P<0.01$ for both hospitals, Figure 2, Table 4). Reserve antibiotics comprised less than one percent of the antibiotic prescribing at both hospitals, however prescribing of reserve antibiotics increased from 2008 to 2017 at the TH (P $<0.01$, Figure 2, Table 4). Prescribing of FDCs of antibiotics (J01R) comprised $8 \%$ of the antibiotic prescribing at the TH and $18 \%$ at the NTH. Prescribing of FDCs increased at both hospitals from 2008 to 2017 ( $P<0.01$ for both hospitals, Figure 2, Table 4).

Patients diagnosed of cellulitis, peritonitis, pneumonia and sepsis accounted for $88 \%$ of the admissions to the NTH and $93 \%$ of the admissions in the TH. Table 5 shows the antibiotic groups (first-choice or secondchoice) prescribed for each of these four diagnoses, which accounted for $75 \%$ of all antibiotics prescribed. Total antibiotic prescribing among patients with cellulitis, peritonitis and pneumonia increased between 2008 and 2017 in both the hospitals $(P<0.01$ for both hospitals, Fig. 1, Table 4). Antibiotic prescribing among patients with sepsis increased between 2008 and 2017 in the NTH $(P=0.03)$ but decreased in the TH $(P<0.01$, Fig. 1, Table 4). Sepsis was the only one of the four diagnoses where antibiotic consumption decreased at one of the hospitals.

\section{Cellulitis}

In the NTH, the two most commonly prescribed antibiotics were second-choice treatments: J01D (32\% of total antibiotics prescribed) and J01R (17\%) [15]. Prescribing of both J01D and J01R increased during the study period, as did prescribing of the recommended treatments (J01CR and J01D) $(P<0.05$ for all, Table 5). In the $\mathrm{TH}$, the most commonly prescribed antibiotics were from the J01CR (19\%) and J01G group (21\%) and prescribing of J01CR increased between 2008 and 2017. ( $P<0.01$, Table 5). At the NTH, prescribing of access, watch and FDCs (J01R) increased from 2008 to 2017 while at the TH, prescribing of access, watch, reserve and FDCs increased ( $P<0.01$ for all categories, at both hospitals).

\section{Peritonitis}

In the NTH, the two most commonly prescribed antibiotics were first-choice treatments for community acquired peritonitis [18]: J01D antibiotics comprised $25 \%$ of antibiotics prescribed, and J01X accounted for $20 \%$ of antibiotics prescribed. Prescribing of $\mathrm{J} 01 \mathrm{X}$ increased during the study period $(P<0.01$, Table 5$)$. In the $\mathrm{TH}$, the two most commonly prescribed antibiotics were first-choice treatments: J01M (16\%) and J01X (26\%), and prescribing of both J01M and J01X groups increased between 2008 and $2017(P<0.01$ for both antibiotic groups, Table 5). In addition, prescribing of J01CR (first-choice treatment for community-acquired peritonitis) increased in both hospitals during the study period. At both hospitals, prescribing of access, watch, reserve and FDCs (J01R) increased from 2008 to 2017 ( $P<0.01$ for all categories mentioned at both hospitals).

\section{Pneumonia}

\section{Sepsis}


In both hospitals, piperacillin with tazobactam (J01CR) group was commonly prescribed, which is adherent with guidelines [19]. In the NTH, J01CR antibiotics accounted for $21 \%$ of all antibiotics prescribed, and J01D accounted for $27 \%$ of all antibiotics prescribed. Prescribing of J01D decreased between 2008 and 2017 ( $P$ $<0.01$, Table 5). In the TH, the most commonly prescribed antibiotics were from the J01CR (19\%) and J01X groups (19\%) and prescribing of both J01CR and J01X decreased between 2008 and 2017. ( $P<0.01$ for both antibiotic groups, Table 5). At the NTH, prescribing of watch and FDCs (J01R) increased from 2008 to 2017 while prescribing of reserve antibiotics decreased. At the TH, prescribing in DDDs per 1000 patient days, of access, watch and FDCs decreased from 2008 to 2017 (Table 4).

\section{Discussion}

According to our knowledge, this is the first study that compares antibiotic prescribing practices for selected infectious diagnoses over a ten years period in two Indian private-sector hospitals. In the NTH, prescribing of antibiotics for all indications, including antibiotics specifically for cellulitis, pneumonia, peritonitis and sepsis diagnoses, increased from 2008 to 2017. In the TH, although antibiotic prescribing practices did not change during the study period, antibiotic prescribing for cellulitis, pneumonia and peritonitis increased and decreased for sepsis. Between 2008 and 2017, prescribing of access, watch and FDC of antibiotics rose in the $\mathrm{NTH}$, and prescribing of watch, reserve and FDCs increased in the TH.

In this study, we analysed adherence to various international recommendations for antibiotic prescribing: the WHO's recommendations for empirical antibiotic treatment for cellulitis and pneumonia, the recommendations for empirical antibiotic treatment from the 'Surviving sepsis campaign' for sepsis and the recommendations of the World Society of Emergency Surgery for peritonitis $[15,18,19]$. Adherence to these international guidelines increased in the TH compared to the NTH during the study period, especially prescribing of antibiotics for peritonitis and pneumonia.

Guidelines on empirical antibiotic treatment are often based on whether an infection is healthcare associated or community acquired. As both bacterial flora and susceptibility patterns vary worldwide, the following factors are important to consider while selecting the most appropriate antibiotic: the bacterium most likely to be the cause of the infection, patient's clinical status, allergies to specific antibiotics and current or previous antibiotic resistance and responses to antibiotic treatment $[1,18,19]$. In this study, most of the patients did not have cultures sent for analysis, as the use of microbiological analyses was limited at both hospitals. The lack of microbiological analyses makes it difficult to comment on the rationale underlying the antibiotic prescription practices in the hospitals. However, prescribing of broad-spectrum antibiotics in both hospitals was high, which is in line with previous reports on prescribing of broad-spectrum antibiotics in Indian hospitals $[12,20]$. As all the patients in the NTH paid for the treatment they received, the patients might have put pressure on their physicians to prescribe broad-spectrum antibiotics. In a qualitative study including 36 Indian doctors, Kotwani et al. reported that doctors faced demands from their patients to prescribe 'strong' antibiotics and that they sometimes prescribed antibiotics because they did not have time to debate with patients due to time constraints in busy health care facilities [21]. The aforementioned factors, as well as the desire to avoid re-consultation, might have contributed to the prescribing of broad-spectrum antibiotics in the hospitals in the present study. 
In the NTH, the FDCs of antibiotics (J01R) were commonly prescribed to all patients, including those with cellulitis, peritonitis, pneumonia and sepsis. In contrast, the FDCs were less frequently prescribed in the TH. Prescribing of the FDCs for all indications increased in the TH during the study period but decreased for diagnoses of pneumonia and sepsis. Prescribing FDCs of antibiotics is not recommended, as they have been shown to drive antibiotic resistance, a common consequence of unnecessarily prescribed antibiotics, often in incorrect doses [22]. Appropriate prescribing of antibiotics requires that the dose be tailored for the individual patient, which is often not possible while prescribing the FDCs. A few FDCs that includes unapproved formulations, are known to be widely used in India [23-26]. In March 2016, the Indian Government banned around 330 FDCs of drugs, of which 63 (19\%) were FDCs of antibiotics [27]. However, there are still more than 118 FDCs of antibiotics available in the Indian market [27]. The presence of medical representatives and lack of local prescribing guidelines may have contributed to the higher prescribing of FDCs of antibiotics in the $\mathrm{NTH}$ as compared with that in the $\mathrm{TH}$, where medical representatives are forbidden, and mainly generic medicines are procured by the management. Previous research demonstrated that pressure from pharmaceutical companies influence physicians' prescribing practices in India [28].

Regardless of the country or setting, access antibiotics should primarily be used to save, whereas watch and reserve antibiotics should be used only for specific and limited indications in critically ill patients or patients with infections caused by bacteria with known antibiotic resistance [17]. In both hospitals, reserve antibiotics comprised less than $1 \%$ of the total antibiotics prescribed. In the $\mathrm{TH}$, access antibiotics were most commonly prescribed (61\% of antibiotics prescribed), followed by watch antibiotics (29\%). However, in the NTH, access and watch antibiotics were prescribed in equal numbers (40\% each). These results indicated that watch antibiotics accounted for a higher proportion of antibiotics prescribed in the NTH than in the TH. Furthermore, in the $\mathrm{TH}$, prescribing of watch and reserve antibiotics for cellulitis or peritonitis increased in both hospitals during the study period, whereas prescribing of these antibiotics for sepsis decreased.

The relatively low incidence of some infectious diseases, such as infective endocarditis, among admissions to the NTH and the TH may be explained by underdiagnosing, which is a major problem in hospitals, as described in a previous study on infective endocarditis in India [29]. In many health care facilities in LMICs, microbiological tests and imaging methods are seldom used due to a lack of access to these diagnostic methods or a lack of time and money $[8,21]$. In only a small number of cases in the present study, samples were sent for microbiological analyses, despite such analyses being readily available in both hospitals. Patient- and prescriber-related factors have been put forward to explain why culture tests are not routinely performed in the hospitals $[12,21,30]$. Patient-related factors include patients not being able to afford the tests or prefer to stay for short periods to pay less at the NTH. Prescriber-related factors might include doctors not having the time to wait for lab results due to overcrowding in the hospitals or an additional factor may be monetary driven, that doctors are paid for the number of patients they admit to the hospital so they might be wishing to see as many patients as possible in a given period [12, 21,30]. Routine use of diagnostic methods, such as microbiological analysis and imaging methods, for patients with suspected infections might contribute to better management of and guidance on antibiotic treatment for infectious diseases to reduce antibiotic overuse.

\section{Methodological considerations}




\section{Strengths and limitations}

A strength of this study is the data collection design. The hospitals included in this study lacked computerized medial record systems, and the data were collected manually, using the same method over a long period of time. As data collection and data entry in the registry were performed manually, there was a risk of missing data. To minimize this risk, the staff who completed the forms and data entry were trained at regular intervals. Another strength of this study was that the same form was used for data collection at both hospitals, which enabled comparisons of antibiotic prescribing between the hospitals. A limitation was that none of the hospitals used microbiological analysis (cultures) consistently. Consequently, most of the diagnoses were based on clinical suspicion. As almost all antibiotic prescribing was empirical, it was not possible to assess whether the antibiotics were rationally prescribed. However, by applying the WHO's antibiotic categories of access, watch and reserve, as well as existing guidelines on empirical prescribing for each diagnosis, the appropriateness of antibiotic prescribing practices in both hospitals could be assessed. Finally, this study included only adult patients. The reasons for this were two-fold: First, the 'defined daily dose' system is based on adult patients. Thus, antibiotic use among paediatric patients cannot be evaluated using the defined daily dose system. Second, the recommendations used to assess rationality in antibiotic prescribing in this study were for adults only.

\section{Conclusions}

Over the ten years period, prescribing of all antibiotic categories, including access, watch and FDCs of antibiotics, increased in the NTH. In the TH, antibiotic prescribing practices did not change significantly, although prescribing of watch, reserve and FDCs of antibiotics increased between 2008 and 2017. Antibiotic prescribing for pneumonia, peritonitis and cellulitis increased in both hospitals between 2008 and 2017. In the TH, antibiotic prescribing for sepsis decreased but increased in the NTH. The results indicate that antibiotic prescribing practices need to be improved in both hospitals, although the $\mathrm{TH}$ generally prescribed more recommended antibiotics and fewer FDCs. Furthermore, the prescribing of recommended antibiotics improved over the study period in the TH. Factors contributing to extensive prescribing of watch antibiotics and FDCs in the NTH could be pressure from pharmaceutical companies and patients, as well as a lack of a local prescribing guidelines. The establishment of antibiotic stewardship programs based on the access, watch and reserve antibiotic categorization, as well as the implementation of locally adapted lists of essential medicines and prescribing guidelines could contribute to improved antibiotic prescribing practices and thus limit the development of antibiotic resistance. Furthermore, the implementation of routine diagnostic methods, such as microbiological analysis, could improve the management of infectious diseases and guide antibiotic therapy decisions for appropriate prescribing of antibiotics. The hospitals included in the present study are typical of those in similar settings in LMICs, and our results are in line with those of previously published studies in this area. The results highlight areas for improvement in antibiotic prescribing practices and same could be anticipated from other similar settings.

\section{Declarations}

\section{Ethics approval and consent to participate}


Data was collected by specially trained nurses at the NTH and the TH. The forms containing patient data were collected regularly and the information was entered to a computerized registry. The forms are kept in security by the research group in Ujjain. Data was registered anonymously, since there were no personal identity numbers entered in the forms. For anonymizing, a unique code was given for each form, with no possibility to track the data to an individual person's identity.

The patients were informed about the research project at the time of admission to the hospitals and were able to refuse their participation without consequences. The study did not affect or cause any changes in the patients' treatment. The study was approved by the ethics committee of Ruxmaniben Deepchand Gardi Medical College, Ujjain (approval numbers 41/2007. 114/2010. 311/2013).

\section{Consent for publication}

Not applicable.

\section{Availability of data and material}

The data that support the findings of this study are available from Ruxmaniben Deepchand Gardi Medical College in Ujjain, but restrictions apply to the availability of these data, which were used under license for the current study, and so are not publicly available. Data are however available from the authors upon reasonable request and with permission of the Institutional ethics committee of the Ruxmaniben Deepchand Gardi Medical College, Ujjain, India.

\section{Competing interests}

The authors declare that they have no competing interests.

\section{Funding}

Swedish Research Council (K2007-70X-20514-01-3, K2010-396 70X-20514-04-3, 2017-01327) and Asia Link (348-2006-6633). MS is the recipient of Erasmus Mundus Lot-15.

\section{Authors' contributions}

MS and CSL conceptualized the study. AD, MS, CSL designed the study. MS was responsible for implementation of the procedure, training of the nurses and data entry staff. MS supervised the process of data collection and entry in the register. $A D$ analyzed the data under supervision of $G M$. AD, GM and MS interpreted the data. AD drafted the manuscript, MS, GM and CSL revised it. All authors approved the final manuscript.

\section{Acknowledgements}

The authors acknowledge the nursing staff of both hospitals involved in the data collection, to the management of both hospitals, to the consultants of the hospitals and Dr V.K. Mahadik (Medical Director of Ruxmaniben Deepchand Gardi Medical College, Ujjain) for the permission and for providing support during the study. 


\section{Abbreviations}

ATC Anatomical Therapeutic Chemical classification system

$\mathrm{Cl}$ Confidence interval

DDD Defined Daily Doses

ESBL Extended spectrum beta lactamase

GLASS Global Antimicrobial Surveillance System

LMIC Low- and middle-income countries

NTH Non-teaching hospital

TH Teaching hospital

VRE Vancomycin-resistant enterococci

WHO World Health Organization

\section{References}

1. Morehead MS, Scarbrough C. Emergence of Global Antibiotic Resistance. Prim Care. 2018;45(3):467-84.

2. Laxminarayan $R$, Matsoso $P$, Pant $S$, Brower $C$, Rottingen JA, Klugman $K$, et al. Access to effective antimicrobials: a worldwide challenge. Lancet. 2016;387(10014):168-75.

3. High levels of antibiotic resistance found worldwide. World Health Organization. 2018. https://www.who.int/mediacentre/news/releases/2018/antibiotic-resistance-found/en/. Assessed 4 February 2020.

4. Global action plan on antimicrobial resistance. World Health Organization. 2015. http://apps.who.int/iris/bitstream/handle/10665/193736/9789241509763_eng.pdf?sequence=1. Assessed 4 February 2020.

5. Lim C, Takahashi E, Hongsuwan M, Wuthiekanun V, Thamlikitkul V, Hinjoy S, et al. Epidemiology and burden of multidrug-resistant bacterial infection in a developing country. Elife. 2016;5.

6. Wilkinson A, Ebata A, MacGregor H. Interventions to Reduce Antibiotic Prescribing in LMICs: A Scoping Review of Evidence from Human and Animal Health Systems. Antibiotics (Basel). 2018;8(1).

7. Pathak A, Mahadik K, Dhaneria SP, Sharma A, Eriksson B, Lundborg CS. Antibiotic prescribing in outpatients: Hospital and seasonal variations in Ujjain, India. Scandinavian Journal of Infectious Diseases. 2011;43(6-7):479-88.

8. Ganguly NK, Arora NK, Chandy SJ, Fairoze MN, Gill JP, Gupta U, et al. Rationalizing antibiotic use to limit antibiotic resistance in India. Indian J Med Res. 2011;134:281-94.

9. Sharma M, Eriksson B, Marrone G, Dhaneria S, Lundborg CS. Antibiotic prescribing in two private sector hospitals; one teaching and one non-teaching: a cross-sectional study in Ujjain, India. BMC Infect Dis. 
2012;12:155.

10. Laxminarayan R, Heymann DL. Challenges of drug resistance in the developing world. 2012;344:e1567.

11. Cunha CB, Opal SM. Antibiotic Stewardship: Strategies to Minimize Antibiotic Resistance While Maximizing Antibiotic Effectiveness. Med Clin North Am. 2018;102(5):831-43.

12. Sharma M, Damlin AL, Sharma A, Stålsby Lundborg C. Antibiotic prescribing in medical intensive care units-a comparison between two private sector hospitals in Central India. Infectious diseases. 2015;47(5):302-9.

13. Landstedt K, Sharma A, Johansson F, Stålsby Lundborg C, Sharma M. Antibiotic prescriptions for inpatients having non-bacterial diagnosis at medicine departments of two private sector hospitals in Madhya Pradesh, India: a cross-sectional study. BMJ open. 2017;7(4):e012974.

14. Guidelines for ATC classification and DDD assignment. World Health Organization. 2019. https://www.whocc.no/atc_ddd_index/. Assessed 2 February 2020.

15. WHO Model List of Essential Medicines - 20th list. World Health Organization. 2017. https://apps.who.int/iris/bitstream/handle/10665/273826/EML-20-eng.pdf?ua=1. Assessed 6 February 2020.

16. Critically important antimicrobials for human medicine, 5th revision 2016. World Health Organization. 2017. https://apps.who.int/iris/bitstream/handle/10665/255027/9789241512220-eng.pdf? sequence=1. Assessed 6 February 2020.

17. McGettigan P, Roderick P, Kadam A, Pollock AM. Access, Watch, and Reserve antibiotics in India: challenges for WHO stewardship. Lancet Glob Health. 2017;5(11):e1075-e6.

18. Sartelli M, Chichom-Mefire A, Labricciosa FM, Hardcastle T, Abu-Zidan FM, Adesunkanmi AK, et al. The management of intra-abdominal infections from a global perspective: 2017 WSES guidelines for management of intra-abdominal infections. World J Emerg Surg. 2017;12:29.

19. Rhodes A, Evans LE, Alhazzani W, Levy MM, Antonelli M, Ferrer R, et al. Surviving Sepsis Campaign: International Guidelines for Management of Sepsis and Septic Shock: 2016. Intensive Care Med. 2017;43(3):304-77.

20. Khan FA, Singh VK, Sharma S, Singh P. A prospective study on the antimicrobial usage in the medicine department of a tertiary care teaching hospital. Journal of clinical and diagnostic research : JCDR. 2013;7(7):1343-6.

21. Kotwani A, Wattal C, Katewa S, Joshi PC, Holloway K. Factors influencing primary care physicians to prescribe antibiotics in Delhi India. Family practice. 2010;27(6):684-90.

22. Shafiq N, Kumar G, Gautam V, Ray P, Malhotra S. Fixed-dose combinations of antimicrobials: A need for special attention. Indian J Med Microbiol. 2016;34(2):208-9.

23. McGettigan P, Roderick P, Kadam A, Pollock A. Threats to global antimicrobial resistance control: Centrally approved and unapproved antibiotic formulations sold in India. British journal of clinical pharmacology: BJCP. 2019;85(1):59-70.

24. Hussain S, Yadav SS, Sawlani KK, Khattri S. Assessment of drug prescribing pattern using world health organization indicators in a tertiary care teaching hospital. Indian J Public Health. 2018;62(2):156-8. 
25. Shanmugapriya S, Saravanan T, Rajee SS, Venkatrajan R, Thomas PM. Drug prescription pattern of outpatients in a tertiary care teaching hospital in Tamil Nadu. Perspect Clin Res. 2018;9(3):133-8.

26. Aravamuthan A, Arputhavanan M, Subramaniam K, Udaya Chander JS. Assessment of current prescribing practices using World Health Organization core drug use and complementary indicators in selected rural community pharmacies in Southern India. J Pharm Policy Pract. 2017;10:1.

27. Ahmad A, Khan MU, Balkrishnan R. Fixed-dose combination antibiotics in India: global perspectives. Lancet Glob Health. 2016;4(8):e521.

28. Bhaskarabhatla $\mathrm{A}$, Chatterjee $\mathrm{C}$. The role of physicians in prescribing irrational fixed-dose combination medicines in India. Social science \& medicine. 2017;174:179-87.

29. Math RS, Sharma G, Kothari SS, Kalaivani M, Saxena A, Kumar AS, et al. Prospective study of infective endocarditis from a developing country. American heart journal : AHJ. 2011;162(4):633-8.

30. Pathak D, Pathak A, Marrone G, Diwan V, Lundborg CS. Adherence to treatment guidelines for acute diarrhoea in children up to 12 years in Ujjain, India-a cross-sectional prescription analysis. BMC Infect Dis. 2011;11:32.

\section{Tables}

Table 1. Antibiotics categorized in access, watch, reserve and fixed dose combinations of antibiotics 


\begin{tabular}{|c|c|c|c|}
\hline $\begin{array}{l}\text { ATC- } \\
\text { code }\end{array}$ & Antibiotic group & Specific antibiotics & $\begin{array}{c}\text { Antibiotic } \\
\text { category }\end{array}$ \\
\hline \multirow{2}{*}{ J01A } & \multirow[t]{2}{*}{ Tetracyclines } & Doxycycline & Access \\
\hline & & Tigecycline & Reserve \\
\hline J01B & Amphenicols & Chloramphenicol & Access \\
\hline $\begin{array}{l}\text { J01 } \\
\text { group } \\
1: \\
\text { J01CA, } \\
\text { J01CE, } \\
\text { J01CF, } \\
\text { J01CG }\end{array}$ & $\begin{array}{l}\text { Penicillins with extended } \\
\text { spectrum, } \\
\text { Beta-lactamase sensitive } \\
\text { penicillins, beta- } \\
\text { lactamase resistant } \\
\text { penicillins, beta- } \\
\text { lactamase inhibitors }\end{array}$ & $\begin{array}{l}\text { Amoxicillin, ampicillin, benzathine } \\
\text { benzylpenicillin, benzylpenicillin, } \\
\text { cloxacillin, phenoxymethylpenicillin, } \\
\text { procaine benzylpenicillin, piperacillin, } \\
\text { tazobactam }\end{array}$ & Access \\
\hline \multirow[t]{2}{*}{ J01CR } & \multirow{2}{*}{$\begin{array}{l}\text { Combinations of } \\
\text { penicillins including } \\
\text { beta-lactamase inhibitors }\end{array}$} & Amoxicillin with clavulanic acid & Access \\
\hline & & Piperacillin with tazobactam & Watch \\
\hline \multirow[t]{3}{*}{ J01D } & \multirow[t]{3}{*}{ Beta-lactam antibiotics } & $\begin{array}{l}\text { Cefalexin, cefazolin, cefadroxile, } \\
\text { cefradine, cefuroxime }\end{array}$ & Access \\
\hline & & $\begin{array}{l}\text { Cefixime, ceftriaxone, cefotaxime, } \\
\text { cefoperazone, cefodoxime, ceftazidime, } \\
\text { meropenem, imipenem, cilastin, } \\
\text { faropenem }\end{array}$ & Watch \\
\hline & & Aztreonam, cefepime, ceftaroline & Reserve \\
\hline J01E & $\begin{array}{l}\text { Sulfonamides and } \\
\text { trimethoprim }\end{array}$ & Sulfamethoxazole with Trimethoprim & Access \\
\hline \multirow[t]{2}{*}{ J01F } & \multirow[t]{2}{*}{ Macrolides } & Clindamycin & Access \\
\hline & & $\begin{array}{l}\text { Azithromycin, clarithromycin, } \\
\text { erythromycin, lincomycin, roxithromycin }\end{array}$ & Watch \\
\hline J01G & Aminoglycosids & $\begin{array}{l}\text { Gentamicin, netilmicin, kanamycin, } \\
\text { tobramycin, streptomycin, amikacin }\end{array}$ & Access \\
\hline $\mathrm{J} 01 \mathrm{M}$ & $\begin{array}{l}\text { Quinolones and } \\
\text { fluoroquinolones }\end{array}$ & $\begin{array}{l}\text { Ciprofloxacin, levofloxacin, moxifloxacin, } \\
\text { norfloxacin, orfloxacin, gemifloxacin, } \\
\text { pazufloxacin, gatifloxacin, prulifloxacin }\end{array}$ & Watch \\
\hline J01R & $\begin{array}{l}\text { Combinations of } \\
\text { antibiotics }\end{array}$ & $\begin{array}{l}\text { Ampicillin with Cloxacillin. } \\
\text { Amoxicillin with Cloxacillin } \\
\text { Azithromycin with Ambroxol } \\
\text { Cefixime with Ornidazole } \\
\text { Cefoperazone with Sulbactam } \\
\text { Ceftriaxone with Sulbactam } \\
\text { Ceftriaxone with Tazobactam } \\
\text { Norfloxacin with Tinidazole } \\
\text { Ofloxacin with Ornidazole } \\
\text { Ofloxacin with Tinidazole } \\
\text { Cefixime with Clavulanate Potassium } \\
\text { Cefixime with Clavulanic Acid } \\
\text { Cefixime with Cloxacilline } \\
\text { Cefixime with Ofloxacin } \\
\text { Cefixime with Tazobactam } \\
\text { Cefotaxime with Sulbactam } \\
\text { Cefpodoxime with Clavulanic Acid } \\
\text { Cefpodoxime with Cloxacillin } \\
\text { Cefpodoxime with Dicloxacillin } \\
\text { Meropenem with Sulbactam } \\
\text { Ceftazidime with Tazobactam } \\
\text { Cefuroxime with Clavulanic Acid } \\
\text { Ciprofloxacin with Ornidazole } \\
\text { Ciprofloxacin with Tinidazole } \\
\text { Efoperazone with Sulbactam }\end{array}$ & $\begin{array}{l}\text { FDCs of } \\
\text { antibiotics }\end{array}$ \\
\hline
\end{tabular}




\begin{tabular}{|l|l|l|l|} 
& & $\begin{array}{l}\text { Levofloxacin with Ornidazole } \\
\text { Cefixime with Azithromycin } \\
\text { Cefpodoxime with Potassium } \\
\text { Clavulanate } \\
\text { Ceftriaxone with Clavulanic Acid }\end{array}$ & \\
\hline J01X & Other antibiotics & $\begin{array}{l}\text { Metronidazole (J01XD01), } \\
\text { nitrofurantoin, tinidazole, ornidazole, } \\
\text { spectinomycin }\end{array}$ & $\begin{array}{l}\text { Access (P01AB01 } \\
\text { Metronidazole } \\
\text { included) }\end{array}$ \\
\cline { 3 - 4 } & & Teicoplanin, vancomycin & Watch \\
\cline { 3 - 4 } & & $\begin{array}{l}\text { Polymyxin B, colistin, fosfomycin, } \\
\text { linezolid, daptomycin }\end{array}$ & Reserve \\
\hline
\end{tabular}

Abbreviations: ATC, Anatomical Therapeutic Chemical Classification; FDC, fixed dose combination.

Table 2. Total number of admissions and included patients each year at the two Indian privatesector hospitals

\begin{tabular}{|r|r|r|r|r|}
\hline & \multicolumn{2}{|c|}{ NTH } & \multicolumn{2}{|c|}{ TH } \\
\hline Year & $\begin{array}{c}\text { Number of } \\
\text { admissions, } \mathbf{n}\end{array}$ & $\begin{array}{c}\text { Patients } \\
\text { included, } \\
\mathbf{n}(\%)\end{array}$ & $\begin{array}{c}\text { Number of } \\
\text { admissions, } \mathbf{n}\end{array}$ & $\begin{array}{c}\text { Patients } \\
\text { included, } \\
\mathbf{n}(\%)\end{array}$ \\
\hline $\begin{array}{r}\text { From April 1st, } \\
2008\end{array}$ & 10480 & $230(2)$ & 6965 & $80(1)$ \\
\hline 2009 & 15384 & $247(2)$ & 10369 & $103(1)$ \\
\hline 2010 & 16126 & $311(2)$ & 11145 & $118(1)$ \\
\hline 2011 & 15136 & $288(2)$ & 12188 & $171(1)$ \\
\hline 2012 & 14414 & $264(2)$ & 10454 & $139(1)$ \\
\hline 2013 & 14627 & $267(2)$ & 9821 & $146(1)$ \\
\hline 2014 & 16473 & $268(2)$ & 13186 & $208(2)$ \\
\hline 2015 & 13740 & $249(2)$ & 12387 & $124(1)$ \\
\hline 2016 & 14165 & $310(2)$ & 16741 & $128(1)$ \\
\hline Until May 31 & & & 5852 & $45(1)$ \\
\hline 2017 & 4121 & $70(2)$ & 109108 & $1262(1)$ \\
\hline Total & 134666 & $2504(1)$ & &
\end{tabular}

Notes: Values are presented in total number of admissions, number of included patients and percentage of total number of admissions.

Abbreviations: n, number; NTH, non-teaching hospital; TH, teaching hospital.

Table 3. Clinical characteristics and antibiotic prescribing among patients with severe infections at two private sector hospitals 


\begin{tabular}{|c|c|c|c|c|c|c|c|}
\hline \multirow[t]{2}{*}{ Patients } & \multicolumn{2}{|c|}{$\begin{array}{l}\text { Number of } \\
\text { patients, } \mathrm{n} \\
\text { (\%) }\end{array}$} & \multicolumn{2}{|c|}{$\begin{array}{c}\text { Patients } \\
\text { prescribed AB, } \\
\text { n (\%) }\end{array}$} & \multirow{2}{*}{$\begin{array}{c}\text { Difference among } \\
\text { patients prescribed } \\
\mathrm{AB}, \\
\text { OR (CI) } \\
\text { P-value } \\
\end{array}$} & \multicolumn{2}{|c|}{$\begin{array}{c}\text { Prescriptions } \\
\mathrm{n} \text { (n of prescriptions } \\
\text { per patients prescribed } \\
\mathrm{AB})\end{array}$} \\
\hline & NTH & $\mathrm{TH}$ & NTH & $\mathrm{TH}$ & & NTH & $\mathrm{TH}$ \\
\hline $\begin{array}{l}\text { All included } \\
\text { patients }\end{array}$ & $\begin{array}{l}2504 \\
(100)\end{array}$ & $\begin{array}{l}1262 \\
(100)\end{array}$ & $\begin{array}{r}2294 \\
(92)\end{array}$ & $\begin{array}{r}1122 \\
(89)\end{array}$ & $1.36(1.08,1.72)$ & 18751 (8) & 24956 (22) \\
\hline Female & $\begin{array}{r}894 \\
(36) \\
\end{array}$ & $\begin{array}{l}301 \\
(24) \\
\end{array}$ & $809(90)$ & $259(86)$ & $1.54(1.01,2.32)$ & $10 / 01$ (0) & $24500(24)$ \\
\hline Male & $\begin{array}{r}1610 \\
(64)\end{array}$ & $\begin{array}{l}961 \\
(76)\end{array}$ & $1485(88)$ & $863(90)$ & $\begin{array}{r}1.35(1.01,1.80) \\
0.03\end{array}$ & & \\
\hline Cellulitis & $\begin{array}{l}388 \\
(15) \\
\end{array}$ & $\begin{array}{l}402 \\
(32) \\
\end{array}$ & $354(91)$ & $\begin{array}{l}362 \\
(90) \\
\end{array}$ & $\begin{array}{r}1.15(0.69,1.91) \\
0.57 \\
\end{array}$ & $3505(10)$ & $8608(24)$ \\
\hline Endocarditis & $7(0)$ & $2(0)$ & $6(86)$ & $1(50)$ & $\begin{array}{r}6(0.04,547.49) \\
0.28\end{array}$ & $33(6)$ & $54(54)$ \\
\hline Epiglottitis & $12(0)$ & $1(0)$ & $11(92)$ & $1(100)$ & - & $57(5)$ & $2(2)$ \\
\hline Meningitis & $\begin{array}{r}186 \\
(7) \\
\end{array}$ & $38(3)$ & $167(90)$ & $27(71)$ & $\begin{array}{r}3.58(1.37,8.93) \\
<0.05 \\
\end{array}$ & $1126(7)$ & $442(16)$ \\
\hline Peritonitis & $\begin{array}{l}431 \\
(17) \\
\end{array}$ & $\begin{array}{l}252 \\
(20) \\
\end{array}$ & $402(93)$ & $\begin{array}{l}233 \\
(92) \\
\end{array}$ & $\begin{array}{r}1.13(0.58,2.14) \\
0.69 \\
\end{array}$ & $4909(12)$ & $6715(29)$ \\
\hline Pneumonia & $\begin{array}{l}761 \\
(30) \\
\end{array}$ & $\begin{array}{l}410 \\
(32) \\
\end{array}$ & $692(91)$ & $\begin{array}{l}366 \\
(89) \\
\end{array}$ & $\begin{array}{r}1.21(0.78,1.83) \\
0.36 \\
\end{array}$ & $4686(7)$ & $6179(17)$ \\
\hline Pyelonephritis & $71(3)$ & $3(0)$ & $68(96)$ & $2(67)$ & $\begin{array}{r}11.33(0.14,262.11) \\
0.16 \\
\end{array}$ & $518(8)$ & $89(45)$ \\
\hline $\begin{array}{l}\text { Septic } \\
\text { arthritis }\end{array}$ & $3(0)$ & $38(3)$ & $3(100)$ & $29(76)$ & 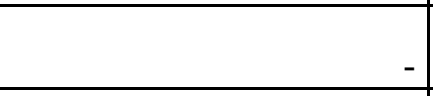 & $15(5)$ & $1159(40)$ \\
\hline Sepsis & $\begin{array}{l}645 \\
(26) \\
\end{array}$ & $\begin{array}{r}116 \\
(9) \\
\end{array}$ & $591(92)$ & $\begin{array}{l}101 \\
(87) \\
\end{array}$ & $1.6(0.82,3.0) 0.11$ & $3902(7)$ & $1708(17)$ \\
\hline
\end{tabular}

Notes: Statistically significant $\mathrm{p}$-values are marked in bold font.

Abbreviations: AB, antibiotic; CI, confidence interval; n, number; NTH, non-teaching hospital; $\mathrm{OR}$, odds ratio; $\mathrm{TH}$, teaching hospital.

Table 4. Description of trends in antibiotic prescribing among patients with severe infections in Ujjain between 2008-2017

\begin{tabular}{|l|r|r|}
\hline & NTH & TH \\
\hline Antibiotic prescribing among specific diagnoses \\
\hline All antibiotics & $13.84(<0.01)$ & $1.82(0.07)$ \\
\hline Cellulitis & $5.72(<0.01)$ & $6.52(<0.01)$ \\
\hline Peritonitis & $14.59(<0.01)$ & $18.52(<0.01)$ \\
\hline Pneumonia & $4.87(<0.01)$ & $7.30(<0.01)$ \\
\hline Sepsis & $2.18(0.03)$ & $-21.91(<0.01)$ \\
\hline Antibiotic prescribing among all included patients \\
\hline Access antibiotics & $11.52(<0.01)$ & $1.78(<0.07)$ \\
\hline Watch antibiotics & $9.63(<0.01)$ & $6.49(<0.01)$ \\
\hline Reserve antibiotics & $-0.76(0.45)$ & $2.54(<0.01)$ \\
\hline FDCs of antibiotics & $14.28(<0.01)$ & $7.31(<0.01)$ \\
\hline Antibiotic prescribing among sepsis patients \\
\hline Access antibiotics & $1.49(0.14)$ & $-16.89(<0.01)$ \\
\hline Watch antibiotics & $3.02(<0.01)$ & $-11.38(<0.01)$ \\
\hline Reserve antibiotics & $-9.32(<0.01)$ & Too few prescriptions \\
\hline FDCs of antibiotics & $3.78(<0.01)$ & $-9.93(<0.01)$ \\
\hline
\end{tabular}


Notes: All values are presented with a value for the slope: $t$ (obtained from linear regression analysis), followed by P-value in parenthesis. A positive $t$ shows a positive trend and a negative $\mathrm{t}$ shows a negative trend. Statistically significant $\mathrm{p}$-values indicates a significant trend and are marked in bold font.

Abbreviations: FDC, fixed dose combination; NTH, non-teaching hospital; TH, teaching hospital.

Table 5. Antibiotics prescribed among patients with severe infections at two private sector hospitals from 2007-2018 
\begin{tabular}{|l|l|l|l|l|l|l|l|l|l|l|}
\hline Year & 2008 & 2009 & 2010 & 2011 & 2012 & 2013 & 2014 & 2015 & 2016 & 2017 \\
\hline
\end{tabular}

Cellulitis NTH

\begin{tabular}{|l|r|r|r|r|r|r|r|r|r|r|r|r|r|}
\hline J01CR & 4.12 & 4.44 & 0.73 & 4.78 & 3.17 & 4.90 & 5.77 & 4.33 & 3.24 & 7.11 & 16 & 2.32 & 0.02 \\
\hline J01D & 13.11 & 9.01 & 1.98 & 11.52 & 5.09 & 4.28 & 12.50 & 7.54 & 14.18 & 3.06 & 32 & 6.33 & $<0.01$ \\
\hline J01R & 6.53 & 5.60 & 3.12 & 2.60 & 4.70 & 3.46 & 3.01 & 6.78 & 6.12 & 1.84 & 17 & 6.97 & $<0.01$ \\
\hline J01X & 9.25 & 15.76 & 3.68 & 3.34 & 1.30 & 1.05 & 1.62 & 1.08 & 1.42 & 1.48 & 15 & 3.31 & $<0.01$ \\
\hline
\end{tabular}

Cellulitis TH

\begin{tabular}{|l|r|r|r|r|r|r|r|r|r|r|r|r|r|}
\hline J01CR & 10.84 & 7.45 & 4.24 & 7.14 & 9.47 & 8.99 & 10.07 & 8.03 & 16.29 & 13.33 & 19 & 4.91 & $<0.01$ \\
\hline J01D & 4.48 & 6.01 & 9.32 & 6.22 & 4.76 & 4.66 & 6.87 & 6.53 & 9.98 & 2.10 & 12 & 5.58 & $<0.01$ \\
\hline J01G & 9.33 & 13.53 & 9.11 & 9.26 & 14.55 & 10.47 & 10.01 & 6.37 & 15.64 & 5.45 & 21 & 0.44 & 0.66 \\
\hline J01M & 10.20 & 8.70 & 3.35 & 5.66 & 9.00 & 4.51 & 4.30 & 3.31 & 9.11 & 6.22 & 13 & 2.66 & $<0.01$ \\
\hline J01X & 6.53 & 3.70 & 7.38 & 6.50 & 6.86 & 10.22 & 7.89 & 3.84 & 9.17 & 3.91 & 13 & 2.27 & 0.02 \\
\hline
\end{tabular}

Peritonitis NTH

\begin{tabular}{|l|r|r|r|r|r|r|r|r|r|r|r|r|r|}
\hline J01CR & 3.71 & 4.26 & 3.85 & 10.23 & 3.06 & 5.70 & 4.45 & 5.89 & 5.67 & 4.40 & 16 & 4.98 & $<0.01$ \\
\hline J01D & 26.28 & 6.43 & 4.54 & 4.34 & 10.36 & 7.35 & 1.41 & 7.78 & 8.04 & 5.06 & 25 & 1.34 & 0.18 \\
\hline J01R & 8.58 & 6.14 & 5.29 & 5.55 & 5.01 & 1.14 & 3.09 & 5.02 & 6.19 & 1.40 & 15 & 8.67 & $<0.01$ \\
\hline J01X & 16.03 & 11.72 & 11.64 & 9.09 & 4.57 & 2.49 & 1.58 & 1.81 & 3.54 & 1.97 & 20 & 10.95 & $<0.01$ \\
\hline
\end{tabular}

Peritonitis TH

\begin{tabular}{|l|r|r|r|r|r|r|r|r|r|r|r|r|r|}
\hline J01CR & 5.84 & 4.39 & 6.68 & 5.55 & 10.92 & 9.13 & 16.54 & 13.44 & 13.36 & 5.35 & 15 & 10.16 & $<0.01$ \\
\hline J01D & 4.00 & 4.95 & 9.63 & 9.44 & 6.87 & 2.76 & 6.04 & 7.64 & 15.87 & 7.73 & 12 & 17.55 & $<0.01$ \\
\hline J01G & 10.08 & 4.65 & 11.08 & 9.94 & 11.84 & 6.49 & 11.43 & 11.87 & 8.64 & 4.08 & 15 & 8.13 & $<0.01$ \\
\hline J01M & 16.05 & 10.72 & 3.27 & 6.40 & 11.99 & 5.83 & 11.60 & 12.86 & 15.42 & 3.56 & 16 & 2.92 & $<0.01$ \\
\hline J01X & 15.75 & 9.55 & 16.85 & 17.73 & 15.44 & 13.92 & 22.64 & 17.30 & 23.05 & 5.24 & 26 & 8.69 & $<0.01$ \\
\hline
\end{tabular}

\section{Pneumonia NTH}

\begin{tabular}{|l|r|r|r|r|r|r|r|r|r|r|r|r|r|}
\hline J01CR & 11.54 & 5.01 & 4.05 & 4.27 & 4.95 & 4.61 & 5.96 & 5.79 & 8.79 & 8.17 & 29 & -0.91 & 0.36 \\
\hline J01D & 7.75 & 6.92 & 4.22 & 8.53 & 3.24 & 2.95 & 1.37 & 4.44 & 4.23 & 4.18 & 22 & -1.38 & 0.17 \\
\hline J01M & 1.00 & 0.49 & 0.47 & 0.50 & 2.41 & 0.83 & 3.98 & 7.34 & 3.47 & 1.18 & 10 & 2.54 & 0.01 \\
\hline J01R & 5.74 & 4.61 & 3.51 & 2.55 & 4.21 & 4.76 & 5.27 & 4.61 & 3.72 & 4.82 & 20 & 5.65 & $<0.01$ \\
\hline
\end{tabular}

Pneumonia TH

\begin{tabular}{|l|r|r|r|r|r|r|r|r|r|r|r|r|r|}
\hline J01A & 16.44 & 11.85 & 14.23 & 8.45 & 13.76 & 10.18 & 7.21 & 2.91 & 2.25 & 18.79 & 25 & 1.81 & 0.07 \\
\hline J01CR & 8.45 & 12.64 & 10.66 & 1.91 & 8.26 & 15.71 & 20.02 & 19.21 & 15.38 & 13.27 & 30 & 6.65 & $<0.01$ \\
\hline J01D & 3.85 & 6.01 & 5.04 & 10.91 & 7.24 & 4.65 & 3.94 & 3.81 & 15.31 & 20.74 & 19 & 12.87 & $<0.01$ \\
\hline J01M & 15.87 & 9.36 & 8.72 & 5.72 & 3.88 & 2.04 & 1.61 & 1.77 & 4.65 & 7.44 & 14 & 1.89 & 0.06 \\
\hline Sepsis NTH \\
\hline J01CR & 5.05 & 3.90 & 2.13 & 1.97 & 2.23 & 2.55 & 3.01 & 6.90 & 3.47 & 6.66 & 21 & 1.10 & 0.27 \\
\hline J01D & 10.74 & 7.47 & 1.19 & 3.27 & 4.63 & 3.86 & 4.77 & 6.37 & 4.29 & 1.70 & 27 & -4.67 & $<0.01$ \\
\hline J01R & 7.55 & 3.66 & 1.71 & 1.33 & 2.09 & 3.36 & 1.84 & 3.07 & 2.63 & 2.76 & 17 & 3.17 & $<0.01$ \\
\hline J01X & 12.22 & 6.54 & 4.51 & 0.99 & 0.79 & 0.00 & 1.28 & 1.02 & 0.72 & 0.00 & 16 & -6.07 & $<0.01$ \\
\hline Sepsis TH & \multicolumn{10}{|c|}{} \\
\hline J01A & 14.61 & 7.67 & 9.59 & 1.83 & 4.31 & 2.95 & 4.26 & 0.00 & 0.00 & 3.13 & 11 & -5.50 & $<0.01$ \\
\hline J01CR & 1.84 & 11.18 & 27.87 & 2.76 & 5.09 & 1.83 & 8.04 & 7.09 & 7.79 & 7.09 & 19 & -5.07 & $<0.01$ \\
\hline J01D & 1.37 & 5.48 & 8.48 & 3.03 & 5.87 & 3.79 & 12.27 & 5.57 & 7.21 & 4.89 & 13 & -5.20 & $<0.01$ \\
\hline J01M & 11.51 & 1.75 & 14.45 & 11.32 & 3.13 & 0.11 & 4.75 & 0.91 & 2.81 & 3.62 & 13 & -8.49 & $<0.01$ \\
\hline J01X & 8.95 & 12.93 & 15.34 & 7.08 & 9.18 & 6.36 & 12.60 & 0.91 & 6.00 & 4.07 & 19 & -15.48 & $<0.01$ \\
\hline
\end{tabular}


Notes: Antibiotics presented comprise $\geq 75 \%$ of the total antibiotic prescribing within each diagnosis group. Numbers are presented in total antibiotic prescribing of antibiotic groups for each year, measured in $\mathrm{DDD} / 1000$ patient days and percentage of the total prescribing of antibiotics for each diagnosis and hospitals during the study period. ${ }^{\mathrm{a}} \mathrm{t}$ is obtained by linear regression, a positive $t$ shows a positive trend and a negative $t$ shows a negative trend of prescribing. Statistically significant p-values indicates a significant trend and are marked in bold font.

Abbreviations: DDD, defined daily doses; NTH, non-teaching hospital; TH, teaching hospital.

\section{Figures}

120

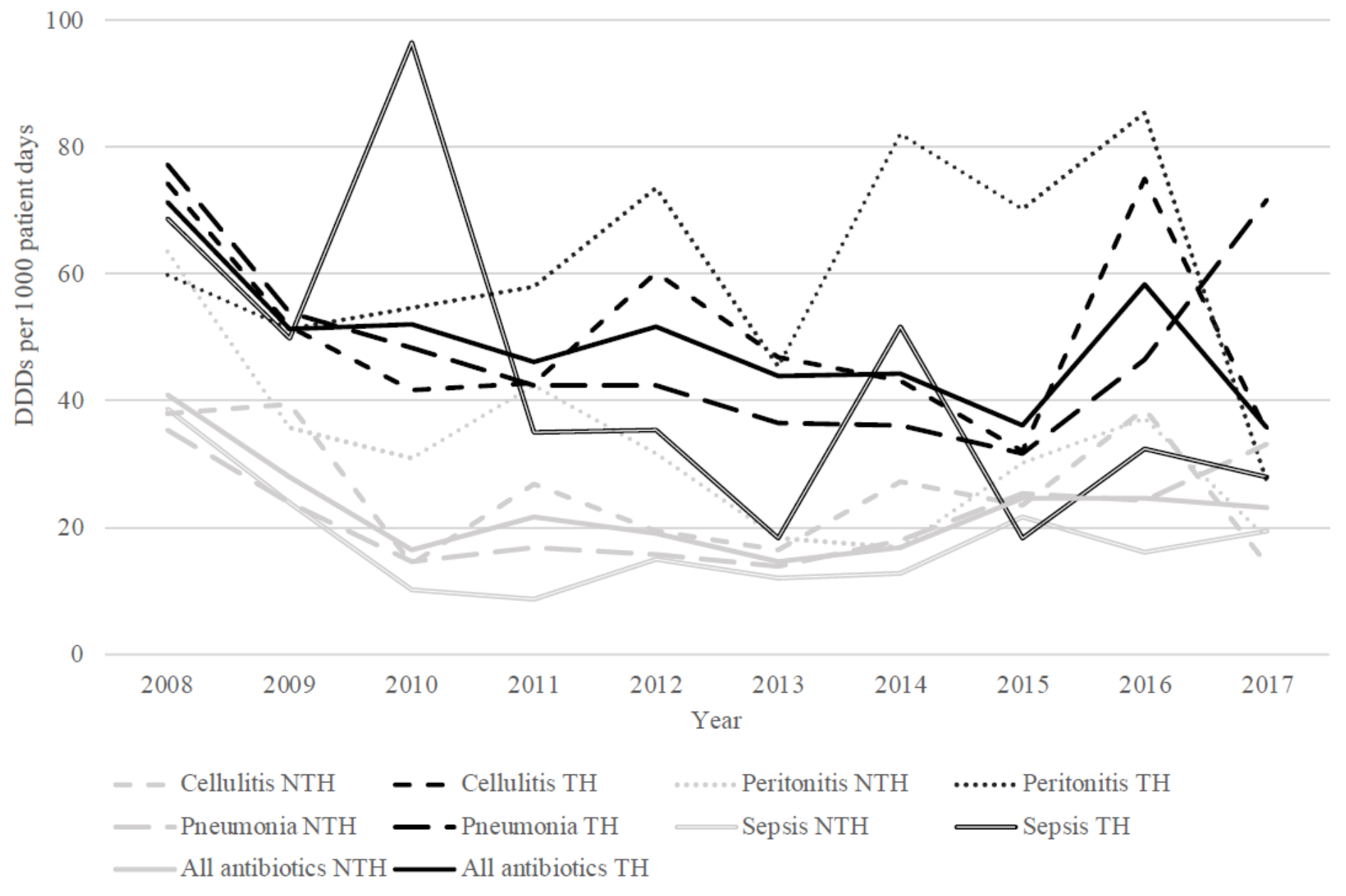

Figure 1

Prescribing of antibiotics among patients with severe infections from 2008 to 2017. Prescribing is presented in DDDs per 1000 patients (y-axis) each year (x-axis). Trends for the slopes are obtained by linear regression 
analysis and are presented together with P-values in Table 4. Abbreviations: DDD, defined daily dosis; NTH, non-teaching hospital; $\mathrm{TH}$, teaching hospital.

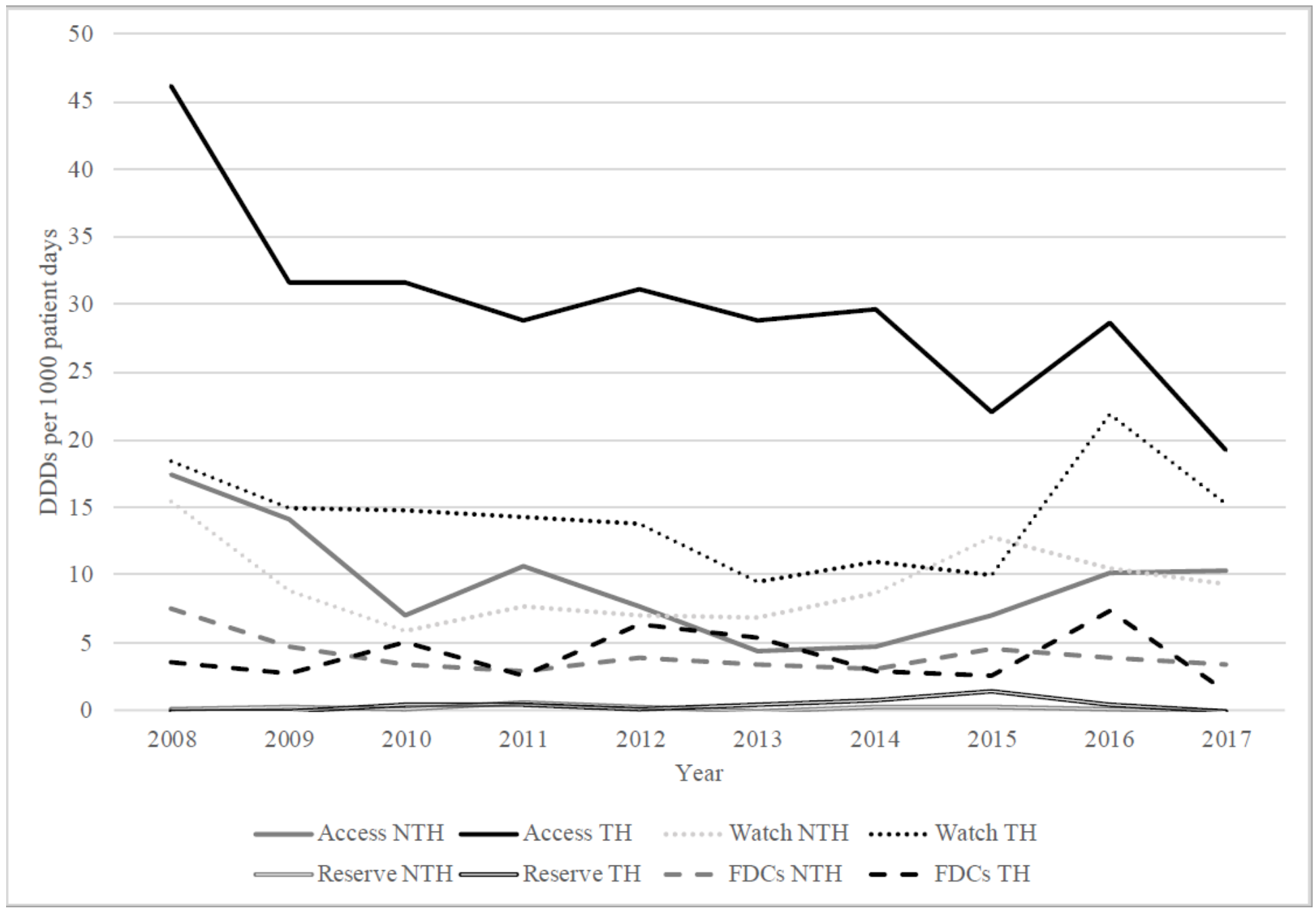

Figure 2

Prescribing of antibiotics categorized by access, watch, reserve and FDCs of antibiotics from 2008-2017. Prescribing is presented in DDDs per 1000 patients (y-axis) each year ( $x$-axis). Trends for the slopes are obtained by linear regression analysis and are presented together with P-values in Table 4. Abbreviations: DDD, defined daily dosis; NTH, non-teaching hospital; TH, teaching hospital. Abbreviations: DDD, defined daily dosis; FDC, fixed dose combinations; $\mathrm{NTH}$, non-teaching hospital; $\mathrm{TH}$, teaching hospital. 


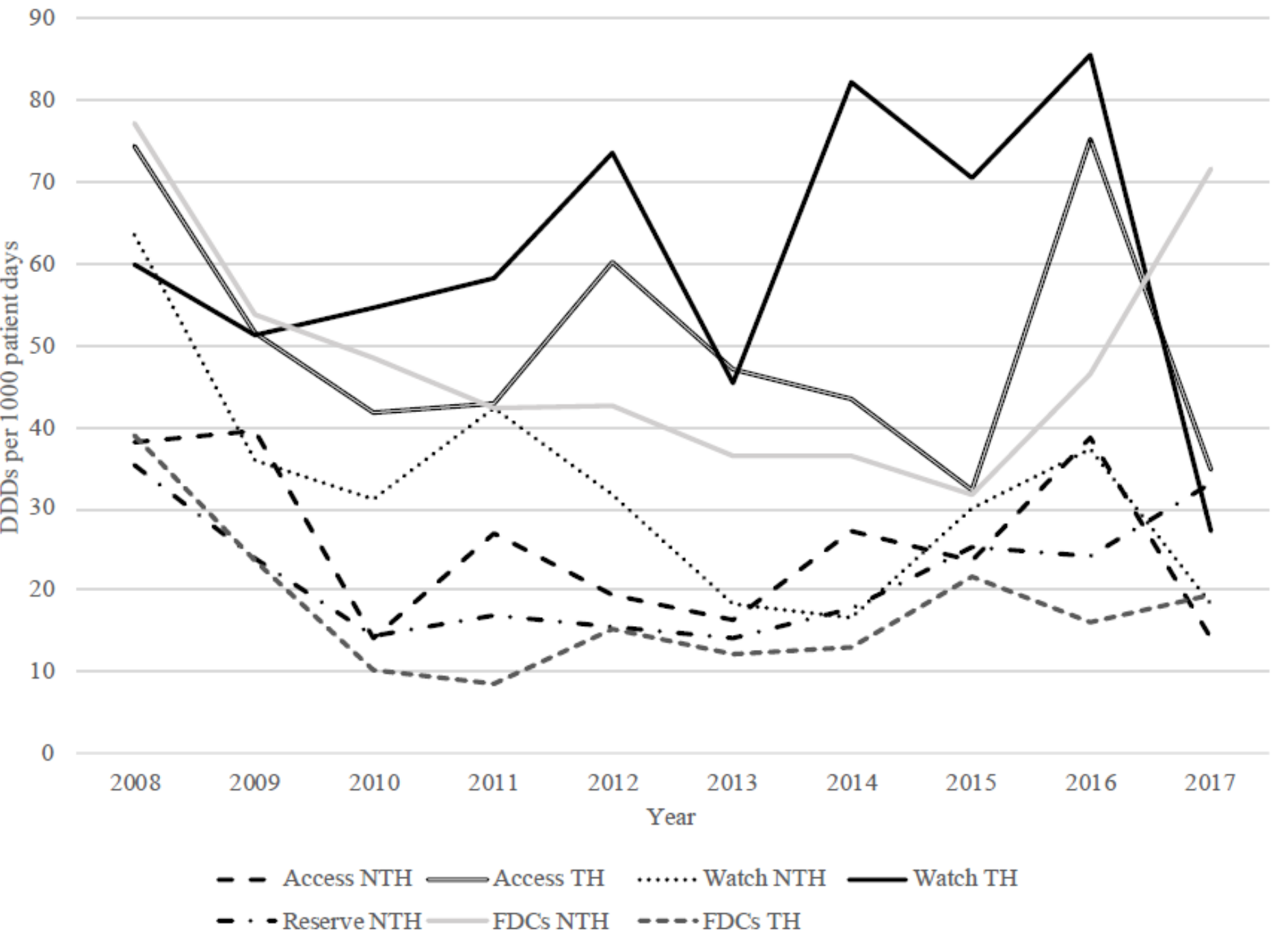

\section{Figure 3}

Title Prescribing of access, watch and reserve antibiotics, and FDCs of antibiotics during 2008-2017 among sepsis-patients. Legend Notes: Each line is presented with t (obtained from linear regression analysis), followed by p-value. Abbreviations: DDD, defined daily dosis; FDC, fixed dose combination; NTH, non-teaching hospital; TH, teaching hospital.

\section{Supplementary Files}

This is a list of supplementary files associated with this preprint. Click to download.

- formulas.docx 